\title{
Correction to: Health effects of milder winters: a review of evidence from the United Kingdom
}

\author{
Shakoor Hajat
}

\section{Correction}

After publication of the article [1], it has been brought to our attention that there is an error in the abstract. The line that reads " $\mathrm{a}{ }^{\circ} \mathrm{C}$ fall during winter months led to reductions of $4.5 \%, 3.9 \%$ and $11.2 \%$ " should say "a 1 。 $\mathrm{C}$ fall during winter months led to increases of $4.5 \%$, $3.9 \%$ and $11.2 \% "$.

Received: 9 January 2018 Accepted: 10 January 2018

Published online: 16 January 2018

\section{Reference}

1. Hajat S. Health effects of milder winters: a review of evidence from the United Kingdom. Environ Health. 2017;16(S1):109. https://doi.org/10.1186/ s12940-017-0323-4. 